Pakistan Journal of Social Research

ISSN 2710-3129 (P) 2710-3137 (O)

Vol. 3, No. 3, September 2021, pp. 362-370,doi.org:10.52567/pjsr.v3i3.258

www.pjsr.com.pk

\title{
THE IMPACT OF MOTIVATION ON EFFICACY OF FACULTY AT UNIVERSITY LEVEL
}

\author{
Maleeha \\ MPhil Scholar, Department of Education, Faculty of Social Sciences, \\ International Islamic University Islamabad, Pakistan \\ Shazia Naureen \\ Assistant Professor, Department of Education, Faculty of Social Sciences, \\ International Islamic University Islamabad, Pakistan \\ Drshazia.naureen@iiu.edu.pk \\ Kainat \\ MPhil Scholar, Department of Humanities Education \& Psychology, \\ Faculty of Social Sciences, Air University, Islamabad, Pakistan
}

\begin{abstract}
The research was a descriptive in nature. The main objective of the current study was to gauge the impact of compensation on the efficacy of university teachers. Survey method was used. Two questionnaires were designed; one for motivations while other coved the performance of university teachers. The study concluded that remunerations have great impact on the performance of university teachers. Therefore, it was recommended that administration of universities may introduce some motivational measures to enhance the performance of teachers. Universities may provide a conducive working environment among teachers in order to create balance the workload.
\end{abstract}

Keywords: Motivation, Extrinsic Motivation, Work Environment, Job Performance.

\section{INTRODUCTION}

Teachers' performance is referred to as multidimensional construct. It measures all the aspects of teaching. This may include subject mastery, communication and lesson planning. Performance of students has been linked with performance of teachers (William, 2010). In a practical perspective, students' performance and achievement is determined by teacher profile. This performance helps the administrators and educators to assure quality improvement in the system of education. It may also useful for educational researchers. They can explore the role of teacher in teaching and learning process (Arain, Hameed, \& Farooq, 2012). Many researchers have highlighted the characteristics of an improved teacher. These characteristics can be seen in student's performance. This study analyzes the effect of compensations on execution of teachers serving at university level. It is one of the major factors that lead the teachers to improve their efficacy.

Improving quality of teachers is major concern in teaching and learning process. Results of many past researchers suggested that compensations have great impact on performance of teachers. Countries evident a positive outcome in teaching learning process who have better compensation packages for teachers and adopt a structure of increase in salary incentives (Arain et al., 2012). The objective was to gauge the effectiveness of compensation on the efficacy of University teachers.

Organizations reward the compensations to the employees for their performance. Employees contribute to the organization and hence, they are rewarded. Compensations promote morality among employees and it also increases motivation. Compensations usually referred to as salary, wages and bonus as it leads to job satisfaction. Satisfaction of employees can be measured by their attitude in the organization. Employees become more productive and motivated, if they are provided with better compensations (Nahar \& Zayed, 2019).

The resources to perform everyday tasks in any organization include machine, material, money and human resource. Resources other than human resources are useless. Outputs are generated with the best use of other resources by the employees (Ojeleye, 2017). Salary given to employee is a fixed amount of money that is paid based on their productive performance. Reward is 
defined as a benefit that is given to employees for performing a task. Every individual is performing respective task and no doubt every individual deserves a reward. It is expected for every employee to be rewarded to increase their motivation. These rewards may be of minimum level and may increase based on their performance. Hence, provision of rewards is essential to the employees to increase their motivation. This may lead to improved performance. The rewards are for the employees who are providing services to improve the performance of organization (Haque, Nair, \& Kucukaltan, 2019). Reward should be paid attention by every organization. One can determine the value of employees in the organization by the way of providing rewards to the employees. Effective and efficient reward system is helpful to determine high performers in the organization. Rewards that have been provided to the employees should be according to the productivity of the employees. An employer must appreciate the work of employees and overtime they make to complete a task (Satka, 2019).

Ojeleye (2017) directed research to the effect of pay on representatives' presentation. Ojeleye led concentrate on 83 workers. Organized survey was utilized to gather information. Pearson relationship and different relapse were utilized to break down the information. Calvin's study depicted that there was the positive relationship between teacher's performance and compensations.

Haque et al. (2019) conducted their study, they included salary, rewards and incentives under the term compensation in their study. They conducted their study on IT firms in Dhaka, Bangladesh. They conducted their study on 204 employees. The results of their study showed the significant relationship and significant impact on the performance of employees.

Wilfred et al. (2014) carried out a research to investigate the effect of compensation on employee performance in the Ministry of Internal Security. Structured questionnaire was used gather data from 107 respondents. The researchers used ANOVA and t-test to analyze the data. Their study concluded that compensation packages lead the employees to the motivation.

Satka (2019) directed a research to explore the effect of remuneration on representative execution in the exchanging organization. Researcher directed a quantitative exploration on five development organizations in Tirana. The researcher deduced in the examination that reward framework impacts the presentation of association. It likewise recommended that prize is straightforwardly relative to the representative presentation.

\section{Statement of the Problem}

Motivation is an essential factor for improving the teaching process. Achievement of students mainly depends on efficacy of teachers. There is a need to evaluate motivation and efficacy of university faculty. Therefore, present research was design to explore the impact of motivation on efficacy of faculty member at university level in the context of higher education in Pakistan.

\section{Objective of the Study}

The main objective of the current study was to gauge the impact of compensation on the efficacy of university teachers.

\section{Hypothesis}

$\mathrm{H}_{0}$ : There is no significant impact of compensation on the efficacy of faculty members.

\section{REVIEW OF LITERATURE}

As one of the components of teaching measures, teachers have assumed a variety of roles, guiding teachers to pass on information, and supporting students to cultivate the ability of learning choices (Aguinis, 2009). The teachers have faced complex commitments and obligations in achieving educational goals, they need to lead the branch of knowledge they teach (Otto \& Ukpere, 2012). They need to show a character suitable for learning as a good role model for students. Therefore, teachers need to streamline their exhibitions in their work (Arain et al., 2012). The complex tasks and obligations of completing the educational goals are consistent with the teacher's motivation, so sincere goals will support the teacher's practice. Teachers become teachers because of their teaching motives (Cheboi, 2014). Assuming that teachers are not motivated, they will not be persuasive in instruction or teaching (Nahar \& Zayed, 2019). The teacher is the main factor that determines the nature of the student's acceptance of teaching. The enthusiasm of teachers has an important influence 
on students and their satisfaction and satisfaction (Davidson, 2007). Teacher job satisfaction is related to teachers' job execution ability, including teachers' tolerance, sense of responsibility and work motivation (Onyambu, 2014).

Dissatisfaction with teachers' job is closely related to teachers' tendency to absenteeism and reduce teaching tasks. Despite the importance of teacher motivation, compared with other expert gatherings, teachers showed a lower level of motivation and a higher level of stress (Davidson, 2007). When the overall meaning of teacher motivation is different from the overall lack of teacher motivation, the obvious uniqueness is obvious. Therefore, teacher motivation is crucial to teaching/learning measurement, many teachers do not have deep motivation (Ojeleye, 2017).

\section{Teachers' Motivation}

Motivation has been generally explored in the other dialectal. As a singular distinction statement, it is an individual trademark, which is affected after a period of time and applies to everyone to varying degrees (Davidson, 2007). Motivation can describe as a characteristic that marks people as special. In addition, the concept of motivation is widely regarded as a dynamic and extremely complex concept (Satka, 2019). It is a basic component in any learning environment, whether it is progress or disappointment. Therefore, motivation is responsible for explaining the reasons why individuals make a particular decision and participate in a particular activity, how much effort they will put into this activity, and how long they will stick to it (Aguinis, 2009).

Motivation is firmly identified with needs. A representative will have motivation when his requirements are met, accordingly the necessities of workers influence their motivation (Davidson, 2007). Necessities can be viewed as physiological or mental insufficiencies that invigorate conduct. They can be solid or powerless and are impacted by natural factors, with the goal that a human's necessities will change at various occasions and in better places (William, 2010).

Teacher motivation, otherwise called the "motivation to teach" alludes to the reasons that emerge from people's intrinsic will to teach and support teaching, (Otto \& Ukpere, 2012) and its power is demonstrated by the work gave to this course of teaching (Ojeleye, 2017). Teacher motivation has created and extended from past decade has seen a stamped expansion in writing in the space of teacher motivation research across different social settings (Cheboi, 2014). As a major commitment to the utilization of motivational theories in the new research area of teachers in their vocation decision, instruction studies and expert responsibility, the uncommon issue was a significant impulse to setting the plan for future teacher motivation research (Davidson, 2007).

\section{Importance of Teacher Motivation}

The meaning of teacher motivation research is likewise undeniable as it is a critical factor firmly identified with various factors in schooling like understudy motivation, educational change, teaching practice and teachers' mental satisfaction and prosperity (Aguinis, 2009). In this manner, motivation is useful for teachers to decide how to design instruction and motivating students (Davidson, 2007). In addition, they further remark for four trademark provisions of teaching motivation:

1. Its basic component is a unique inner desire to teach academic and social conversation (inner/professional part).

2. It relies on relevant factors and is regularly combined with the requirements and calls of the organization and the work environment.

3. This motivation not only means having the motivation to teach, but also in the process of becoming a deeply rooted profession as a teacher.

4. Teachers' motivations are very subtle, because teachers are constantly affected by incredibly positive and negative influences (Abos, Haerens, Sevil, Aelterman, \& Garcia-Gonzalez, 2018).

Despite the fact that teacher motivation basically gets from a professional drive, it is pivotal to remember that this kind of motivation is amazingly delicate (Davidson, 2007). In this manner, it is illogical to accept that teachers, who are continually presented to both amazing positive and negative impacts, will have an inspirational perspective and high motivation consistently (Aguinis, 2009). 


\section{Types of Motivation}

Teachers' inner and extrinsic needs types of motivation use inner motivation to accomplish something, which leads to continuation (Deci, Ryan, Gagne, Leone, Usunov, \& Kornazheva, 2001). The arrangement of impetus to invigorate an activity and the course of intention of a person to complete an errand is term as motivation. Teachers have both intrinsic and extrinsic necessities (Cheboi, 2014). A teacher who is intrinsically motivated may attempt an assignment for the good of its own, for the satisfaction it gives or to the sensation of achievement and self-completion (Abos et al., 2018). Then again, an extrinsically motivated teacher might play out the action or obligation to get a prize like compensation. Researchers expresses that teachers with an inner locus of control are under less pressure and are more fruitful in teaching. In this way, students of these teachers feel less school related pressure and make higher scores in their appraisals (Davidson, 2007).

\section{Intrinsic Motivation}

The intrinsic motivation alludes to play out an action for its inborn satisfactions as opposed to for some separate result (Aguinis, 2009). When intrinsically motivated, individuals participate in exercises that interest them, and they do as such unreservedly. With a full feeling of volition and without the need of material rewards or imperatives (Deci et al., 2001). Individuals who are intrinsically motivated feel that they are doing an action since they have decided to do as such intentionally and in light of the fact that the action addresses a test to their current abilities and expect them to utilize their inventive capacities (Nahar \& Zayed, 2019). This sort of motivation is viewed as not really set in stone as in the justification behind doing the movement is connected exclusively to the singular's good sentiments while playing out the assignment (Davidson, 2007).

Moreover researchers proposes that social conditions can work with or prevent intrinsic motivation by supporting as opposed to foiling individuals' natural mental necessities (Ojeleye, 2017). Actual association between intrinsic motivation and satisfaction of the requirements for independence and ability have been plainly illustrated, and some work proposes that satisfaction of the requirement for relatedness, basically from a distal perspective, (William, 2010) likewise be significant for intrinsic motivation. In any case, that individuals will be intrinsically motivated distinctly for exercises that hold intrinsic interest for them, exercises that have the allure of curiosity, challenge, and elegant worth (Cheboi, 2014). To comprehend the motivation for those exercises, we need to look all the more profoundly into the nature and elements of extrinsic motivation. An action of a person which comes from the individual craving, wish, individual interest and execution is considered as an intrinsic motivation (Satka, 2019).

Although intrinsic motivation is obviously a significant sort of motivation, a large portion of the exercises individuals do are not intrinsically motivated (Otto \& Ukpere, 2012). Various exercises in work associations are not intrinsically fascinating and the utilization of procedures, for example, interest to improve intrinsic motivation isn't generally attainable (William, 2010).

\section{Extrinsic Motivation}

Extrinsic motivation, as opposed to intrinsic motivation, requires an instrumentality between the movement and some detachable outcomes like unmistakable or verbal rewards (Abos et al., 2018). So satisfaction comes not from the actual action but instead from the extrinsic results to which the action leads (Aguinis, 2009). That is, the conduct isn't performed for the good of its own, however rather to get a prize or to stay away from some discipline once the conduct has finished (Nahar \& Zayed, 2019). Starting conceptualizations saw intrinsic and extrinsic motivation as being invariantly opposing. Intrinsic motivation was viewed not really set in stone, while extrinsic motivation was thought to mirror an absence of self-assurance (Davidson, 2007).

However, later research has demonstrated that extrinsic motivation doesn't really sabotage intrinsic motivation and that it might even improve it, suggesting that extrinsic motivation is invariantly controlled (Aguinis, 2009). These discoveries brought about a more refined investigation of extrinsic motivation. While featuring the various types of extrinsic motivation and the context oriented factors that either advance or block disguise and coordination of the guideline for these practices (Cheboi, 2014). In particular, different kinds of extrinsic motivation were recognized that contrast in their level of independence or self-assurance, contingent upon the degree to which 
individuals have been fruitful in disguising the at first outside guideline of the conduct (Ojeleye, 2017).

Extrinsic motivation permits an individual to work consequently of rewards or to keep away from discipline. The Intrinsic motivation is set to have more impact on individual contrasted with extrinsic motivation (Aguinis, 2009). Intrinsic motivation communicates a movement of individuals who drew in on task on own purpose, without anticipating any impetus in their demonstration (William, 2010). Extrinsic motivation is likewise necessary to upgrade the interest in an action to foster interest. The substantial rewards and other type of motivators motivate an individual extrinsically. Professionally, teachers need to teach in a concentration and discipline educational organization climate (Zhang, 2014).

\section{Job Satisfaction}

Teacher job satisfaction and motivation are vital to the consistent development of educational frameworks all throughout the planet. Job satisfaction and motivation are very important to the existence of teachers, because they constitute the key reason for work. The teacher's ability motivates them to perform well (Aguinis, 2009). They also saw promotion opportunities, due favors, strong division of labor among teachers, accessibility of teacher guidance, good working conditions and job security increased their enthusiasm (Davidson, 2007). Researchers show that due to low wages, helpless teaching conditions and ugly management status, low teacher confidence and low quality of teacher work and life, teachers are extremely disappointed in performance and lack motivation. Almost every teacher is trying to meet their lack and development requirements (Cheboi, 2014).

In the analysis of organizations, it has been analyzed that organizations with the good performance shows that they successfully achieved their objectives. AMO model can be used to illustrate the performance of employees. The term AMO refers to A=Ability, M=Motivation and $\mathrm{O}=$ Opportunities (Aguinis, 2009). Employees always work to be an effective in organization. They must have ability to work, appropriate skills and significant knowledge to be an effective in organization. Organizations may also enhance employees' skills and knowledge by providing training to them (Nahar \& Zayed, 2019). It is mandatory for an organization to motivate the employees as to best put their skilled services in progress of organization (Haque et al., 2019). If an organization assembles their process of work in a way that every employee gets the opportunity to contribute in it, it would give profit to the organization. This success may also be achieved if the employees are given equal opportunities of decision making, better communication and opportunity of working in groups (Satka, 2019).

Reward management system includes the designing, implementing and maintaining the reward system. This reward system leads to the improvement in performance of individual, team and organization (Satka, 2019).

The satisfaction of these necessities is the main factor for their participation and unavoidable realization of the expressed personal or authoritative goals (Haque et al., 2019). Although hypothetical ideas are required, contemporary hypotheses, such as intelligence assessment hypotheses, consider different factors that motivate people to complete assigned tasks. This exacerbates the destructive influence of extrinsic rewards on intrinsic motivation (Deci et al., 2001).

Therefore, there is no compelling reason to provide extrinsic rewards to people who are supported by sports because of their intrinsic interest, satisfaction, and the normal values associated with them. As long as the compensation is paid on time and paid regularly, teachers will usually remain satisfied and remain active. In addition, researchers recognize that installment payments, allowances, and promotions are key factors that shape teachers' work mentality (Aguinis, 2009). 


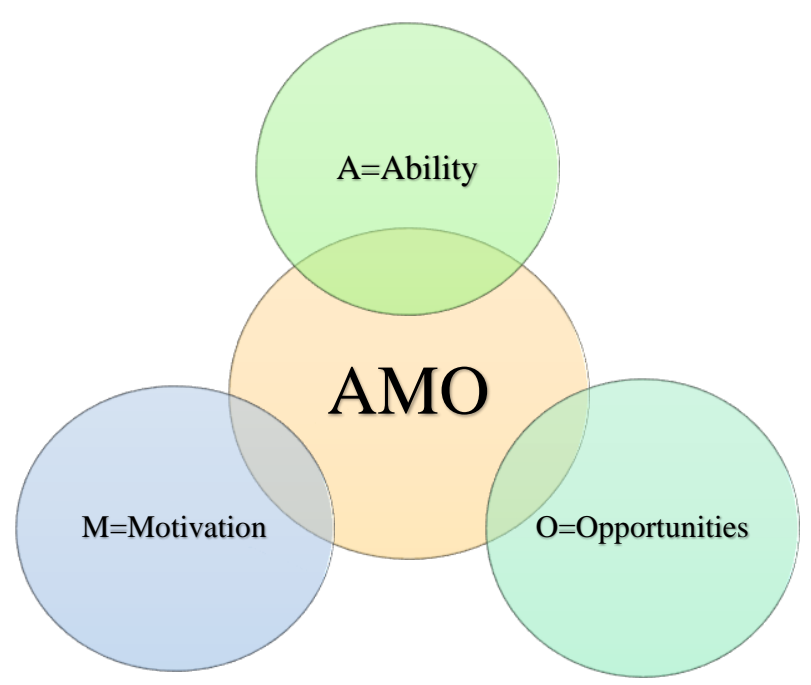

Figure 1.1: AMO Model

Teacher motivation normally related to their job attitude, their desire to participate in educational interactions in the educational institutions atmosphere, and their interest in learning discipline and control, especially in the classroom (Cheboi, 2014). A teacher is a person who interprets the thinking and goals of education as information and delivers it to students in the classroom. The important duty of working with young people in school lies with teachers (Davidson, 2007).

Teachers ensure and maintain their job satisfaction, it seems that the progress of their students is particularly urgent (Abos et al., 2018). The strength of the educational framework usually depends on the nature of its teachers. It is a teacher who helps transform a person into an individual with creative thinking, insight and discipline, just as the country transforms into a learning society (Ojeleye, 2017). Dealing with difficulties both inside and outside the class exhausted teachers and hindered their prosperity. Both internal and external motivations increase job satisfaction (Otto \& Ukpere, 2012)

In addition to establishing the link between motivation and job satisfaction in this review, researchers also need to discover the unique influence of extrinsic and intrinsic motivation on teacher satisfaction (William, 2010). The influence of motivation on execution markers shows that intrinsic motivation is preferable to extrinsic motivation in terms of expected execution (Remi et al., 2011). Previous studies on teacher motivation show that because the educational institution's internal and external factors faculty members (teachers) are energetic, and have a better impact on students (Cheboi, 2014). Moreover, studies has found that teachers are considered to be lack of motivation, which can be explained by teachers' absenteeism in job (Davidson, 2007). Absenteeism is a kind of reluctant behavior, which will have a negative impact on ones' performance (Aguinis, 2009).

Similarly, the literature shows that teachers' responsibilities should be reduced and administrative preparations should be improved. These violations in writing provide a rich foundation for further examination of the different effects of internal and external motivations on teachers' job satisfaction. Finally, the teacher's motivation seems to be very important, because it can predict not only the teacher's participation and success rate, but also the student's participation and other results.

\section{METHODOLOGY}

The research is based on survey. The study focused on the remunerations and efficiency of University faculty. The independent variable was remunerations and the dependent variable was the efficiency of university teachers. Three universities of Islamabad, Pakistan were included in population. Four similar departments were selected having 354 faculty members. The included departments were: Linguistics, International Relations, Management Sciences and Psychology. Total teachers included in the sample were 178. Through stratified random sampling, equal proportion from each university was selected in sample. To collect data, two questionnaires were constructed for teachers. The questionnaires were based on motivation and efficacy. The questionnaires were 
developed by the researchers keeping in view the conditions of universities. Performance of teachers was gauged through individual performance questionnaire. The data were collected using self-data collection technique. The data were extensively analyzed in SPSS using e regression analysis.

\section{RESULTS AND ANALYSIS}

$\mathbf{H}_{\mathbf{0}}$ : There is no significant impact of compensation on the efficacy of faculty members.

The regression analysis shows;

Table 1: Model Summary (Compensations)

\begin{tabular}{|l|l|l|l|l|}
\hline Model & $\mathrm{R}$ & $\mathrm{R}^{2}$ & Adj. $\mathrm{R}^{2}$ & Std. Error of the Estimates \\
\hline & 0.430 & 0.185 & 0.179 & 9.392 \\
\hline
\end{tabular}

The correlation coefficient is 0.430 . The value of $\mathrm{R}^{2}$ is 0.185 , which means $18.5 \%$ change in teacher's efficacy due to working conditions. The value of $\mathrm{R}$ square represents that there is effectiveness of compensation on the efficacy of faculty members at university level.

Table 2: ANOVA (Compensations)

\begin{tabular}{|l|l|l|l|l|l|}
\hline Model & Sum of Squares & Df & Mean Square & F & Sig. \\
\hline Regression & 2603.584 & 1 & 2603 & 29.516 & .000 \\
\hline Residual & 11467.277 & 130 & 88.209 & & \\
\hline Total & 14070.811 & 131 & & & \\
\hline
\end{tabular}

The ANOVA table is a hypothesis test table for regression. According to the table, it can be concluded that the regression equation is effective (29.516), $\mathrm{p}=.00$. The value of ANOVA (.00) is less than 0.05 which suggests that compensation significantly effects efficacy of teachers. Thus, it is deduced that the prediction researcher made was rejected and alternate was accepted.

Table 3: Coefficients (Compensations)

\begin{tabular}{|c|c|c|c|c|c|}
\hline \multirow[t]{2}{*}{ Model } & \multicolumn{2}{|c|}{ Unstandardized Coefficients } & \multirow{2}{*}{$\begin{array}{l}\text { Standardized Coefficients } \\
\text { Beta }\end{array}$} & \multirow[t]{2}{*}{$\mathrm{T}$} & \multirow[t]{2}{*}{ Sig. } \\
\hline & B & Std. Error & & & \\
\hline (Constant) & 124.737 & 2.933 & & 42.534 & .000 \\
\hline Compensations & 2.419 & 0.445 & 0.430 & 5.433 & .000 \\
\hline
\end{tabular}

This table 4.25 provides information about the coefficients and helps in constructing regression equations. According to the beta value of 0.430 in the table, it indicates that compensations have a positive effect on the efficacy of faculty. The p-value is .000, which is less than 0.05 , which in turn indicates that compensation has significant impact on efficacy. Thus, the null hypothesis was rejected and alternate was accepted. 


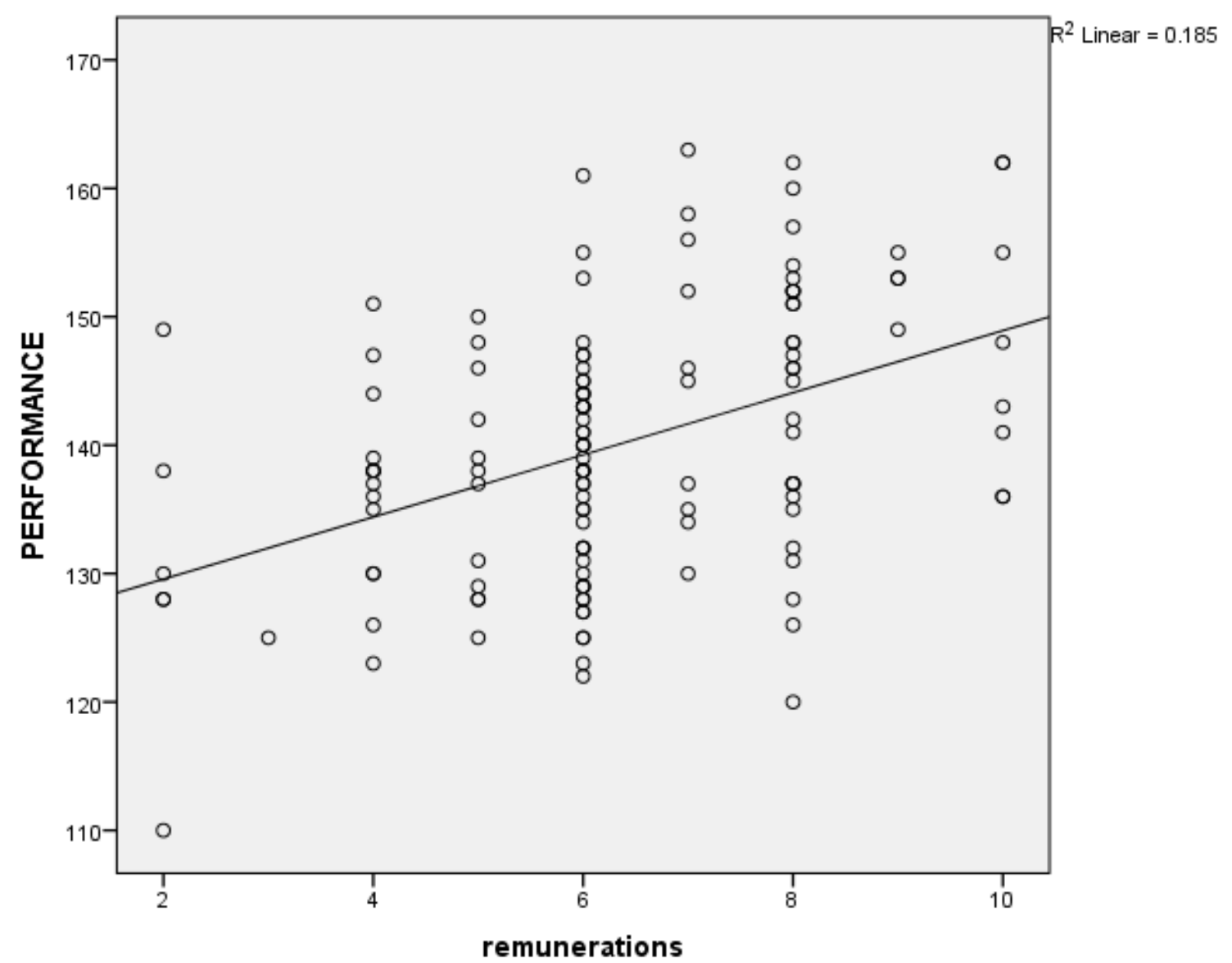

Scatter plot 4.6 Effectiveness of Compensations and efficacy of faculty members

The above scatter plot predicts the positive impact of compensations on teachers. As the compensations score increases the score for performance of teachers, increases. The scatter plot rejects the null hypothesis.

\section{CONCLUSIONS AND RECOMMENDATIONS}

The research concludes that motivation is an important variable to increase the efficacy and productivity of faculty members. It is considered one of major factor that determines the effect of education. Previous research has shown that a motivated university faculty member may work efficiently for the quality of teaching and learning. Giving advantage bundles and additions to the teachers altogether influence the performance of university teachers. Remunerate teachers for their endeavors motivate them and improve their performance. Compensation is an important factor to upgrade the performance of university teachers and to improve their efficacy.

After conducting the research, following recommendations were made:

1. In order to increase the job efficacy of faculty members, specific measures may be required.

2. It may be recommended that compensations may be provided to the teachers on the completion of specific task by the university.

3. It may be additionally suggested that the quality teaching and learning may be appreciated with special increments for the faculty members. Special increments may motivate teachers to perform better and improve their performance. This may in turn upgrade their teaching quality. 


\section{REFERENCES}

Aguinis, H. (2009). Performance management (2nd ed.).

Arain, G. A., Hameed, I., \& Farooq, O. (2012). Integrating workplace affect with psychological contract breach and employees' attitudes. Global Business and Organizational Excellence: A Review of Research and Best Practices , 31 (6), 50-62.

Cheboi, D. K. (2014). Influence of extrinsic motivation on employee's performance in Moi Teaching and Referral hospital Eldoret, Kenya. The University of Nairobi.

Davidson, E. (2007). The Pivotal Role of Teacher Motivation in Tanzanian Education. The Educational Forum, 157-166.

Haque, A. u., Nair, S. L., \& Kucukaltan, B. (2019). Management And Administrative Insight For The Universities: High Stress, Low Satisfaction And No Commitment. Polish Journal of Management Studies , 236-255.

Nahar, S., \& Zayed, N. M. (2019). An Analysis of the Impact of Remuneration on Employee Motivation: A Case Study on Unilever, Bangladesh. Symbiosis Online Publishing.

Ojeleye, Y. C. (2017). he Impact of Remuneration on Employees' Performance : A Study of Abdul Gusau Polytechnic, Talata-Mafara and State College of Education Maru, Zamfara State. Nigerian Chapter of Arabian Journal of Business and Management Review , 34-43.

ONYAMBU, C. (2014). Analysis of the Effect of Teacher Motivation on Kcse Performance: A Case Of Masimba Division, Masaba South District, Kenya. Kenyatta University.

Otto, G., \& Ukpere, W. I. (2012). National Security and Development in Nigeria. African Journal of Business Management, 6765-6770.

Remi, A. J., Adegoke, A.-A. I., \& Toyosi, D. S. (2011). An Empirical Study of the Motivational Factors of Employees in Nigeria . International Journal of Economics and Finance, 227233.

Satka, E. (2019). The Impact Of Remuneration On Employee Performance In The Trading Company. NA.

William, A. N. (2010). Employee Motivation and Performance. Mikkeli University of Applied Sciences.

Yusoff, W., Kian, T. S., Talha, M., Idris, M. (2013). Herzberg's Two Factors Theory on Work Motivation: Does it Work for Today's Environment? Global Journal of Commerce and Management Perspective, 2(5), 18-22

Zalwango, M. (2014). The Role of Motivation in Enhancing Teachers' Performance in Private Primary Schools A Case of St. Mary's International Schools. University of Tanzania.

Zhang, X. (2014). Factors that motivate academic staff to conduct research and influence research productivity in Chinese Project 211 universities. Australia: University of Canberra. 